\title{
Pulmonary effects of inhalation of spark-generated silver nanoparticles in Brown-Norway and Sprague-Dawley rats
}

Joanna Seiffert ${ }^{1}$, Alison Buckley², Bey Leo ${ }^{3}$, Nicholas G. Martin ${ }^{4}$, Jie Zhu' ${ }^{1}$, Ranran Dai ${ }^{1}$, Farhana Hussain ${ }^{1}$, Chang Guo ${ }^{2}$, James Warren², Alan Hodgson², Jicheng Gong5, Mary P. Ryan ${ }^{3}$, Junfeng (Jim) Zhang ${ }^{5}$, Alexandra Porter ${ }^{3}$, Terry D. Tetley ${ }^{1}$, Andrew Gow ${ }^{6}$, Rachel Smith ${ }^{2}$ and Kian Fan Chung ${ }^{1 *}$ (D)

\begin{abstract}
Background: The increasing use of silver nanoparticles (AgNPs) in consumer products is concerning. We examined the potential toxic effects when inhaled in Brown-Norway (BN) rats with a pre-inflammatory state compared to Sprague-Dawley (SD) rats.

Methods: We determined the effect of AgNPs generated from a spark generator (mass concentration: 600-800 $\mu \mathrm{g}$ / $\mathrm{mm}^{3}$; mean diameter: 13-16 nm; total lung doses: 8 [Low] and 26-28 [High] $\mu \mathrm{g}$ ) inhaled by the nasal route in both rat strains. Rats were sacrificed at day 1 and day 7 after exposure and measurement of lung function.

Results: In both strains, there was an increase in neutrophils in bronchoalveolar lavage (BAL) fluid at $24 \mathrm{~h}$ at the high dose, with concomitant eosinophilia in BN rats. While BAL inflammatory cells were mostly normalised by Day 7, lung inflammation scores remained increased although not the tissue eosinophil scores. Total protein levels were elevated at both lung doses in both strains. There was an increase in BAL IL-1 $\beta$, KC, IL-17, CCL2 and CCL3 levels in both strains at Day 1, mostly at high dose. Phospholipid levels were increased at the high dose in SD rats at Day 1 and 7, while in BN rats, this was only seen at Day 1; surfactant protein D levels decreased at day 7 at the high dose in SD rats, but was increased at Day 1 at the low dose in BN rats. There was a transient increase in central airway resistance and in tissue elastance in BN rats at Day 1 but not in SD rats. Positive silver-staining was seen particularly in lung tissue macrophages in a dose and time-dependent response in both strains, maximal by day 7. Lung silver levels were relatively higher in $\mathrm{BN}$ rat and present at day 7 in both strains.
\end{abstract}

Conclusions: Presence of cellular inflammation and increasing silver-positive macrophages in lungs at day 7 , associated with significant levels of lung silver indicate that lung toxicity is persistent even with the absence of airway luminal inflammation at that time-point. The higher levels and persistence of lung silver in BN rats may be due to the pre-existing inflammatory state of the lungs.

Keywords: Lungs, Silver nanospheres, Inhalation, Inflammation

\footnotetext{
* Correspondence: f.chung@imperial.ac.uk

${ }^{1}$ Airways Disease, National Heart \& Lung Institute, Imperial College London,

Dovehouse St, LondonSW3 6LYUK

Full list of author information is available at the end of the article
} 


\section{Background}

Silver nanoparticles (AgNPs) are often suspended in a liquid which can be aerosolised or used in a solid form and are widely used as anti-microbials in consumer products especially for textiles, personal hygiene products, medical equipment, wound dressings, respiratory devices, catheters and disinfectant sprays. Therefore, humans run the risk of inhaling AgNPs [1]. What is known about the potential pulmonary toxicity of inhaled AgNPs has been limited to studies in rodents. Subchronic inhalation of AgNPs induced mild, dosedependent pulmonary inflammation and alterations in pulmonary function [2-6], with evidence that inhaled AgNPs may also enter the systemic circulation to become distributed to extra-pulmonary organs such as the liver and brain $[2,7,8]$. Exposure of rats to AgNP aerosols for 90 days led to modest increased pulmonary function changes, with evidence of genotoxicity and accumulation of tissue macrophages [9], with persistence of lung function and inflammatory changes for up to 12 weeks after cessation of exposure [10]. On the other hand, studies using lower inhaled doses have reported minimal or no toxicity [7, 11-13]. By contrast, direct instillation of AgNPs produced higher levels of inflammation, oxidative stress and cytotoxicity compared to AgNP inhaled at similar doses [14-16].

In our previous study, the inflammatory response induced by intratracheal instillation of AgNPs was dependent on particle size with a greater pulmonary inflammatory response with a $20 \mathrm{~nm}$ size than an $110 \mathrm{~nm}$ size but with little influence imposed by citrate or polyvinyl phosphate-capping [15]. We also observed a pulmonary inflammatory response characterised by an intense eosinophilia and neutrophilia in the BrownNorway (BN) rat compared to a predominantly neutrophilic response in Sprague-Dawley (SD) rats. The response to AgNPs by direct inhalation into lungs, which would be the main route of exposure if humans were exposed to AgNPs from consumer products, remains unclear particularly in the potential differences in the response between the 2 rat strains. The $\mathrm{BN}$ rat is known to readily develop features of allergic asthma, namely lung eosinophilia and bronchial hyperresponsiveness (BHR) following sensitisation and exposure to allergens and possess features of chronic lung inflammation in contrast to the SD rat [17-20].

AgNPs from consumer products are more likely to be inhaled, and the potential toxic effects of AgNPs will certainly depend on the route on entry of these NPs. Therefore, in order to characterise further the bioreactivity of inhaled AgNPs in the lungs, we have studied the effect of freshly-generated uncoated silver nanoparticles produced by a spark discharge generator. We determined the threshold lung deposited dose on the lung inflammatory response and cytokine levels. An important determining factor of the pulmonary response is the interactions of these particles with the lung lining fluid constituents that include dipalmitoylated phospholipid (DPPC) and surfactant-specific proteins A, B, C and D, which influence the aggregation, dissolution and uptake of these nanoparticles by pulmonary macrophages and alveolar cells and hence their cytotoxicity [21-23]. We therefore measured the distribution of the silver particles in the lungs, assayed silver levels, and related these to the surfactant composition and lung function changes. We determined whether there would be differences in these parameters between the 2 rat strains.

\section{Methods}

\section{Generation of silver nanoparticle aerosol and exposure system}

Aerosols of AgNPs were generated using a spark generator (DNP 4000, Palas, Karlsruhe, Germany) by the homogeneous nucleation of vapour produced between two electrodes $(5 \mathrm{~mm}$ length and $1 \mathrm{~mm}$ diameter silver wire; Premion ${ }^{\mathrm{TM}} 99.999$ \% purity, Alfa Aesar ${ }^{\mathrm{TM}}$, Heysham, $\mathrm{UK}$ ) in an inert argon atmosphere at a flow rate of $5 \mathrm{~L} \mathrm{~min}^{-1}$, as previously described [24]. The rate of primary particle production and final size was dependent on the sparking frequency $(90-300 \mathrm{~Hz})$. The particles were passed through a krypon-85 charge neutraliser (Model 3077A, TSI Incorporated, Shoreview, MN, USA) and were diluted with oxygen and nitrogen to give a total aerosol flow-rate of $9 \mathrm{~L} \mathrm{~min}^{-1}$. This was led into a custom-built nose-only exposure manifold consisting of 4 chambers as previously described [24]. Animals were held in restraining tubes attached to the chamber ports, thus each had an individual aerosol supply directed to the nose area.

\section{Characterisation and monitoring of AgNPs}

Aerosol mass concentrations were determined gravimetrically using Pallflex ${ }^{\odot}$ emfab $^{\mathrm{T}}$ filters (Pall Life Sciences, Ann Arbor, MI, USA) with the aerosol drawn at $2 \mathrm{~L}$ min ${ }^{-1}$ with continuous monitoring using a $\mathrm{TEOM}^{\mathrm{m}}$ ambient particulate monitor (Model 1400a, Thermo Scientific, Franklin, MA, USA) [24]. The AgNP aerosol was immediately diluted to prevent coagulation using a Palas ${ }^{\circ}$ ejector dilution system (Model VKL 100, Palas GmbH, Karlsruhe, Germany). HEPA-filtered compressed air was supplied to the diluter, drawing a sample flow rate of $0.12 \mathrm{~L} \mathrm{~min}^{-1}$ from the exposure chamber and giving a dilution ratio of $150 \pm 3 \%$. A condensation particle counter (CPC model 3775, TSI Inc., Shoreview, MN, USA) continuously monitored the concentration of particle numbers with aerosol particle size distribution determined using a scanning mobility particle sizer (SMPS; model 3936 N76, TSI Inc., Shoreview, MN, USA) and 
aerosol particle shape using high resolution transmission electron microscopy (TEM) (JEOL 3000 F, JEOL Inc., Tokyo, Japan) [24]. Projected area equivalent diameters were calculated for $>1500$ particles randomly selected using the image analysis software Image J (http://imagej.nih.gov/ij/).

\section{Dose estimation}

Estimates of the deposited dose, D ( $\mu \mathrm{g})$, in the lung and alveolar regions were determined using the formula, $\mathrm{D}=$ $\mathrm{C} \times \mathrm{MV} \times \mathrm{T} \times \mathrm{DE} \times 10^{-6}$, where $\mathrm{C}\left(\mu / \mathrm{m}^{3}\right)$ is the aerosol mass concentration, $\mathrm{MV}(\mathrm{ml} / \mathrm{min})$ the rat minute ventilation, $\mathrm{T}(\mathrm{min})$ the exposure duration, and $\mathrm{DE}$ the deposition efficiency. The minute ventilation was derived from measurements of tidal volume (TV) and breathing frequency (f) of 6 rats of similar weight to those used in this study made using head-out plethysmograph (EMMS, Bordon, UK) for the duration of noseonly inhalation experiments similar to those described here. The average MV, TV and f were $190 \mathrm{~mL} / \mathrm{min}$, $1.6 \mathrm{ml}$ and $130 \mathrm{~min}^{-1}$ respectively. The deposition efficiencies for the lung and alveolar regions, of 31 and $21 \%$, respectively, were calculated using the multiplepath particle dosimetry (MPPD) model (version 2.11, Applied Research Associates, Inc.) [25] using the aerosol CMD and GSD (Table 1) and the breathing parameters indicated above.

\section{Study design}

The experiments were performed within the legal framework of the United Kingdom under a Project License granted by the Home Office of Her Majesty's government. The researchers hold Personal Licenses provided by the Home Office to perform the experiments in the rat species described here (Project Licence number: PPL 70/7581). These experiments were approved by the Imperial College BioSciences Animal Ethics Committee.

Male pathogen-free Sprague-Dawley (SD) (10-12 weeks, 250-320 g) and Brown-Norway (BN) rats (10-12 weeks, 260-380 g) were purchased from Harlan, UK and housed under filter tops. Rats were randomly assigned into groups and exposed for $3 \mathrm{~h}$ on one day (low dose) or for $3 \mathrm{~h}$ on four consecutive days (high dose). Three exposure conditions were defined: filtered air only controls for $3 \mathrm{~h}$ on 4 consecutive days, low dose AgNP exposure and high dose AgNP exposure (Table 1). Following exposure, the rats were returned to their cages for either $24 \mathrm{~h}$ or 7 days.

\section{Respiratory mechanics}

Respiratory mechanics was measured by the forced oscillation technique at pulmonary end- expiratory pressures (PEEPs) of $3 \mathrm{~cm} \mathrm{H} \mathrm{H}_{2} \mathrm{O}$. Rats were anesthetised with ketamine $(80 \mathrm{mg} / \mathrm{Kg})$ and Xylazine $(10 \mathrm{mg} / \mathrm{Kg})$ i.p. and the depth of anaesthesia was quantified by loss of pedal reflex and by pulse oximetry, using the MouseOx Plus [STARR Life Sciences Corp., Oakmont, PA]. Rats were ventilated through a tracheostomy $(10 \mathrm{~mL} / \mathrm{Kg}$ air at 90 breaths per minute) using a computer-controlled ventilator (Spira, EMMS, UK). Three successive deep lung inflations $\left(30 \mathrm{cmH}_{2} \mathrm{O}\right)$ were performed to standardise volume history. Tdal breathing was interrupted by an $8 \mathrm{~s}$ broadband input signal, containing multiple frequencies between 0.5 and $20 \mathrm{~Hz}$. Respiratory impedance was calculated at each frequency using the Fast Fourier transformation of the pressure and flow signals. As a function of frequency, the impedance ( $\mathrm{Zrs}$ ) data can be separated into both resistance $\left(\mathrm{R}_{\mathrm{L}}\right)$ and elastance $\left(\mathrm{E}_{\mathrm{L}}\right)$ spectrawhich were fitted to a constant phase model which partitions the respiratory mechanics into the central airway $(\mathrm{Rn})$ and coefficients of tissue damping (G) and tissue elastance $(\mathrm{H})$ [26].

\section{Bronchoalveolar lavage (BAL)}

BAL was performed as previously described [15]. Differential cell counts were performed on cytology of BAL. BAL supernatants were stored for analysis of various analytes.

Table 1 Characterisation of spark generated silver nanoparticles and lung burden on each of the exposure conditions for the two rat strains

\begin{tabular}{|c|c|c|c|c|c|c|}
\hline & \multicolumn{3}{|c|}{ Sprague-Dawley rats } & \multicolumn{3}{|c|}{ Brown-Norway rats } \\
\hline & Control & Low dose & High dose & Control & Low dose & High dose \\
\hline Count Median Diameter (nm) & - & $13.4 \pm 1.0$ & $14.1 \pm 2.3$ & - & $15.9 \pm 0.8$ & $15.7 \pm 2.8$ \\
\hline Geometric Standard Deviation & - & $1.60 \pm 0.03$ & $1.58 \pm 0.06$ & - & $1.58 \pm 0.02$ & $1.56 \pm 0.06$ \\
\hline Concentration $/ \mathrm{cm}^{3}$ & $<1$ & $(4.50 \pm 0.21) \times 10^{7}$ & $(4.55 \pm 0.70) \times 10^{7}$ & $<1$ & $(3.89 \pm 0.18) \times 10^{7}$ & $(3.68 \pm 0.48) \times 10^{7}$ \\
\hline Mass concentration $\left(\mu \mathrm{g} / \mathrm{m}^{3}\right)$ & - & $801 \pm 33$ & $670 \pm 49$ & - & $791 \pm 32$ & $617 \pm 25$ \\
\hline Exposure duration (mins) & 720 & 180 & 720 & 720 & 180 & 720 \\
\hline Lung burden $(\mu \mathrm{g})$ & 0 & 8 & 28 & 0 & 8 & 26 \\
\hline Alveolar dose $(\mu \mathrm{g})$ & 0 & 6 & 19 & 0 & 6 & 18 \\
\hline
\end{tabular}




\section{Tissue processing and staining}

Paraffin blocks were prepared from lungs and sections stained with hematoxylin and eosin (H \& E) and carbolchromotrope for visualisation of eosinophils as previously described [15]. The lung inflammatory response was measured on a 0-3 scale, as previously defined [15]. Eosinophils in the lamina propria of largest airways in each lung section were counted around $5 \times 2$ nd-3rd generation large airways of $\sim 10 \mathrm{~mm}$ in length. Eosinophils up to $2 \mathrm{~mm}$ from each airway were counted and expressed as eosinophils per millimetre of basement membrane length.

We also used a Silver Enhancing Kit (Cat no: SE100, Sigma-Aldrich, Saint Louis, USA) to visualise silver nanoparticles using light microscope with positive cells appearing black. Uptake into cells in walls of bronchi or blood vessels, alveoli septa and alveolar space of the left lung lobe were counted. Twenty fields covering the whole left section were counted and data are expressed as number of positive silver cells per field.

\section{Measurement of silver in lungs}

We used different inductively-coupled plasma mass spectrometry (ICP-MS) methods for each rat species. For the Sprague-Dawley rats, the concentration of silver in lung lobes was quantified by 7700 ICPMS machine (Agilent Technologies) following digestion of tissue samples. A standard reference material was analysed with samples (National Research Council Canada (LUTS-1) non-defatted lobster hepatopancreas) and the detection limit for the analysis was $5 \mathrm{ng}$ per sample. For the Brown-Norway rats, we used 7900 ICPMS machine (Agilent Technologies) on snap-frozen tissue. After freeze drying, tissues were digested by microwave and ICPMS performed in no-gas mode using mass 107 as the quantifier and mass 71 as the internal standard. The ICP-MS was calibrated using silver standards diluted from a 1 ppm stock.

\section{Measurement of malondialdehyde}

BAL malondialdehyde (MDA) was measured using a HPLC system with fluorescent detection (Waters, Milford, MA, USA) set at $532 \mathrm{~nm}$ for the excitation wavelength and $553 \mathrm{~nm}$ for the emission wavelength. A Nova-Pak C18 column (Waters, Milford, MA, USA) was used with a mobile phase that was composed of 40 methanol and $60 \%$ water containing $50 \mathrm{mM} \mathrm{KH}_{2} \mathrm{PO} 4$ $(\mathrm{pH}=6.8)$. The detection limit, extraction recovery and analytical precision were $1.8 \mathrm{nM}, 75.9$, and $2.2 \%$, respectively.

\section{Total phospholipid and surfactant proteins in BAL}

BAL supernatant was separated into two fractions using differential centrifugation. $1 \mathrm{~mL}$ of BAL from the first wash was centrifuged at $18,000 \mathrm{rpm}$ for $30 \mathrm{~min}$ at $4{ }^{\circ} \mathrm{C}$ to obtain large and small aggregate fractions. The large aggregate (LA) fraction (pellet) contains phospholipids, tubular myelin, lamellar bodies, large vesicles, SP-A, B and $C$. The supernatant contains the small aggregate fraction (SA) consisting of small vesicles, SP-D and little surface functional surfactant [27]. The LA was resuspended in $40 \mu \mathrm{L}$ of physiological saline and $5 \mu \mathrm{L}$ was separated into organic and aqueous fractions by a chloroform and methanol extraction. The lower layer containing the organic fraction was dried under nitrogen. Total organic phosphorus was extracted using a perchloric acid digestion $(70 \%)$ for one hour at $200{ }^{\circ} \mathrm{C}$, with potassium phosphate standards treated in the same way as the samples and assayed using the method of Bartlett [28]. Organic phospholipid was expressed as $\mu \mathrm{g}$ of total organic phosphate in $5 \mu \mathrm{L}$ LA, equivalent to $1 /$ $5 \mathrm{~mL}$ of BAL. Protein concentrations in the LA and SA were determined by the Bio-rad assay. SP-D was measured in whole BAL supernatants by ELISA [Cusabio Biotech Co., Suffolk, UK] and SP-B inthe LA fraction by ELISA [Cusabio Biotech Co., Newmarket, Suffolk, UK.

\section{Cytokine and chemokine levels in BAL}

Cytokines and chemokines including KC, CCL11 (eotaxin), Interferon (IFN)- $\gamma$, IL-1 $\beta$, IL-4, IL-6, IL-13, IL17A, CCL2 (MCP-1) and CCL3 (MIP-1 $\alpha$ ) were measured in BAL supernatants using a Milliplex MAP rat cytokine panel (Millipore Analayte Kit Finder, Millipore Ltd, Watford, UK) according to the manufacturer's specifications.

\section{Data analysis}

Data analysis was performed using Prism 5 software. Data were treated non-parametrically as data was generally not normally distributed when tested using the Shapiro-Wilk normality test. A non-parametric ANOVA (Kruskal-Wallis test) was performed at each time point and comparison of the means of the multiple groups was assessed by Dunn's post-hoc test. $\mathrm{P}$ values $<0.05$ were considered significant.

\section{Results \\ AgNP dose in the lungs}

The AgNPs had an average count median diameter (CMD) spanning between $13.4 \pm 1.0 \mathrm{~nm}$ and $15.9 \pm$ $0.8 \mathrm{~nm}$ on the different days of exposure with particle number concentrations between $3.68 \pm 0.48 \times 10^{7}$ and $4.55 \pm 0.70 \times 10^{7} / \mathrm{cm}^{3}$ (Table 1; Fig. 1). Mass concentrations measured gravimetrically ranged from $617 \pm 25$ to $801 \pm 33 \mu \mathrm{g} / \mathrm{m}^{3}$. Figure 1 shows representative images of separate Ag nanospheres collected during exposures, illustrating their spherical form. In SD rats, low and high lung doses were estimated using deposition fractions 


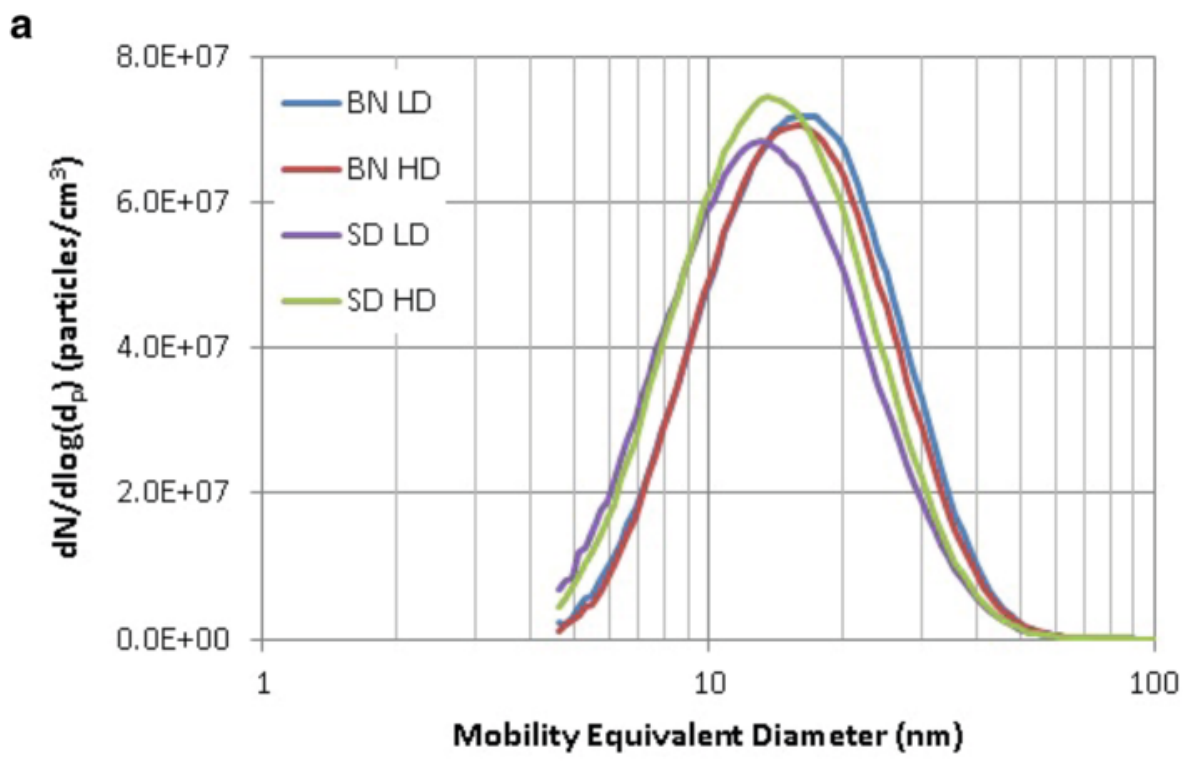

b

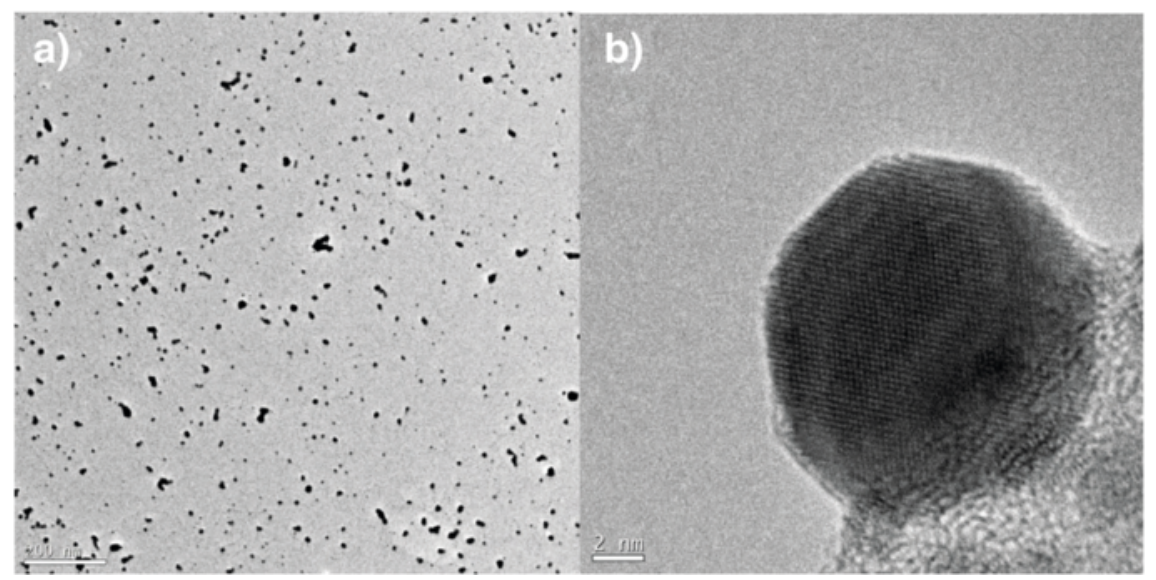

Fig. 1 Panel a: Density of particles as a function of the diameter of silver nanoparticles measured during each of the experimental conditions for each rat strain. BN-LD: Brown Norway rats exposed to low dose; BN-HD: Brown Norway rats exposed to high dose; SD-LD: Sprague-Dawley rats exposed to low dose; SD-HD: Sprague-Dawley rats exposed to high-dose. Panel b: Representative high resolution transmission electron microscopy (TEM) images of aerosol particles delivered to the exposure manifold at 12,000X magnification (scale bar $200 \mathrm{~nm}$ ) (Panel $\mathbf{B}$ a) and 800,000X magnification (scale bar $2 \mathrm{~nm})($ Panel $\mathbf{B}$ b)

from the MPPD model as 8 and $28 \mu \mathrm{g}$ respectively, while in $\mathrm{BN}$ rats, these were 8 and $26 \mu \mathrm{g}$. The equivalent values for alveolar deposition were 6 and $19 \mu \mathrm{g}$ for the $\mathrm{SD}$ rats and 6 and $18 \mu \mathrm{g}$ for the $\mathrm{BN}$ rat.

\section{Quantification and localisation of silver in lung tissue}

Silver levels in the lungs of SD rats exposed to an estimated deposited dose of $28 \mu \mathrm{g}$ of AgNP particles were $9.97 \pm 2.79 \mu \mathrm{g} / \mathrm{g}$ (wet weight) at $24 \mathrm{~h}$. Assuming a typical rat lung weight of $1 \mathrm{~g}$ this suggests significant clearance within the first $24 \mathrm{~h}$, and lower levels of $4.99 \pm 2.21 \mu \mathrm{g} / \mathrm{g}$ wet weight at day $7(P<0.05)$, indicate further clearance had occurred from the lung by this time (Fig. 2 a). The silver concentration in $\mathrm{BN}$ rat lung at $24 \mathrm{~h}$ was
$74.46 \mu \mathrm{g} / \mathrm{g}$ dry weight). Typically lung dry weight is $\sim 20 \%$ of wet weight so this corresponds to around $15 \mathrm{ug} / \mathrm{g}$ wet weight, which is higher by $50 \%$ compared to that found in the SD rats. For the BN rats, there was a non-significant reduction measured at Day 7 (Fig. 2 b), which suggests slower clearance from the $\mathrm{BN}$ rat lung.

In $\mathrm{BN}$ rats, there was a clear dose-dependent increase in the number of silver-positive staining cells in the lung at both 1 and 7 days post inhalation, this dosedependent trend was less clear for the SD rats, particularly at 1 day where the number for both doses were very similar (Fig. $2 \mathrm{c} \& \mathrm{~d}$ ). The numbers of silver positive stained cells were between 2 and 3 times higher for the $\mathrm{BN}$ compared to the SD rats for the high dose exposure. 


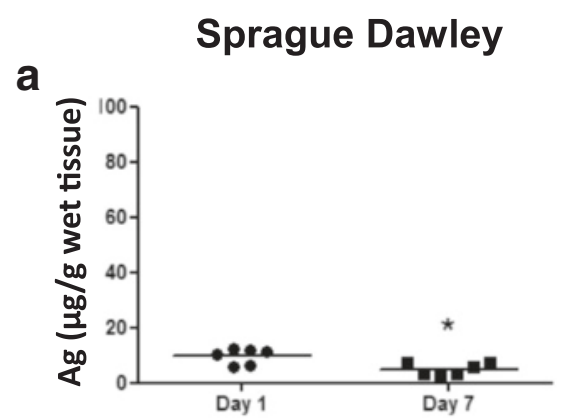

b

Brown Norway
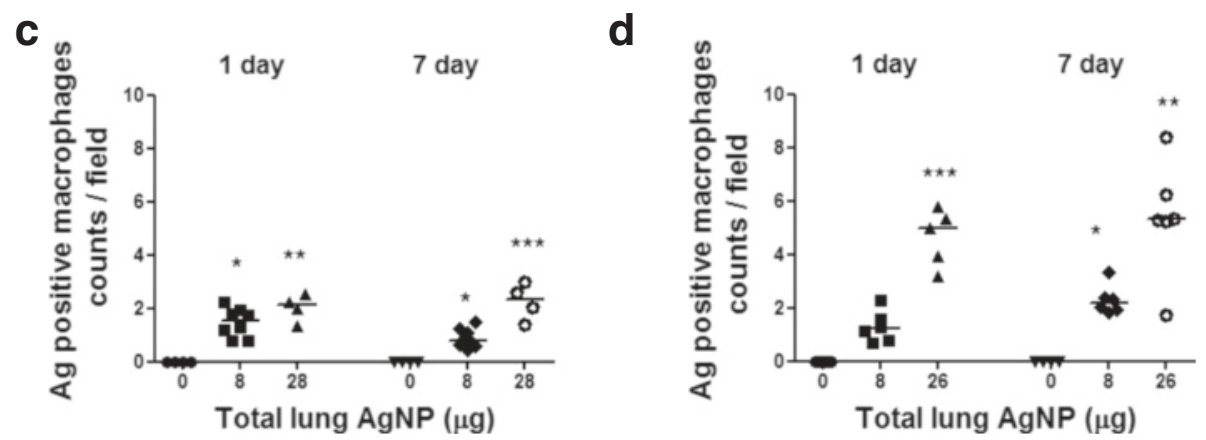

Fig. 2 Panels a \& b: Silver quantification using ICP-MS in lung tissue following inhalation of the high dose of freshly-generated silver nanoparticles. In both rat strains, there was a reduction in lung silver content at Day 7 compared to Day 1, although this only reached statistical significance in the Sprague-Dawley rats. The silver lung content was higher in Brown-Norway rats compared to Sprague-Dawley rats. Panels c \& $\mathbf{d}$ : Counts of macrophages staining positive for silver in the lung tissue of Sprague Dawley and Brown Norway rats exposed to silver nanoparticles at 1 and 7 days post inhalation at each lung dose deposition. Data for individual rats are shown with the median for each group denoted as a horizontal bar. ${ }^{*} P<0.05$, ${ }^{* *} P<0.01,{ }^{* * *} P<0.001$ versus the air only control within each time-point

For both $\mathrm{SD}$ and BN rats numbers of stained cells at 1 and 7 days were similar, indicating no consistent timedependence.

Silver staining was not observed in non-exposed SD and BN lungs (Fig. 3 a \& d). There were black silver particles observed at $24 \mathrm{~h}$ post-AgNP inhalation. Silver positivity at $24 \mathrm{~h}$ was as strong as at 7 days after AgNPs inhalation in both rat strains. Silver-positive cells consisted mainly of macrophages scattered in the alveolar space and lung interstitium of SD lungs (Fig. 3 b \& c). Silver-positive macrophages were embedded within the inflammatory cells which infiltrate the alveolar septa and lamina propria of blood vessels and airway mucosa and were deposited in granulomas of BN lungs (Fig. 3 e \& f). Silver particles were also observed on the luminal surface and on surface epithelium and subepithelial connective tissue of terminal bronchioles, scarcely at day 1 but more prominent at day 7 (Fig. 3).

\section{Lung inflammatory changes}

Following inhalation of silver, there was a mild inflammation with a few inflammatory cell infiltrations in the bronchial and vascular walls and alveolar septa in SD rat lungs (Fig. 4b \& d) compared to the control airexposed rats (Fig. 4a \& c). Overall, tissue inflammation scores were increased in lungs of SD rats at both day 1 and 7 and at both exposure doses with the scores remaining unchanged during that period (Fig. 5a). In $\mathrm{BN}$ rats, there was a high level of baseline inflammation that remained unchanged after inhalation of AgNPs at both levels of exposure and on both day 1 and day 7 (Fig. 5c). Areas of inflammation consisting of eosinophils, neutrophils, and mononuclear cells in $\mathrm{BN}$ rat lungs could be seen (Fig. 3e \& f). Eosinophil counts in the airway wall were increased in $\mathrm{BN}$ rats at day 1 after the $28 \mu \mathrm{g}$ exposure dose but not at day 7 (Fig. 5d). There was no eosinophil increase in the SD lung tissue (Fig. 5b).

\section{$B A L$ inflammatory cells}

In $\mathrm{SD}$ and $\mathrm{BN}$ rats, total cell numbers increased at 1 day post inhalation of the high $28 \mu \mathrm{g} \operatorname{AgNP}(P=0.0002 \& p$ $<0.02$, respectively), and in $\mathrm{SD}$ rats, this remained elevated at day 7 (Fig. 6). Low doses of AgNP $(8 \mu \mathrm{g})$ did not elicit an increase in cells. The increase in total cells was reflected in an increase in neutrophils $(P=0.0002)$ in SD rats, while there was both an increase in neutrophils $(P<0.02)$ and eosinophils $(P<0.01)$ in $\mathrm{BN}$ rats. Neutrophil numbers fell but remained elevated in SD rats at day $7(P=0.009)$. There was also a small increase in lymphocyte numbers at the high dose exposure in SD rats $(P<0.03$; data not shown). 


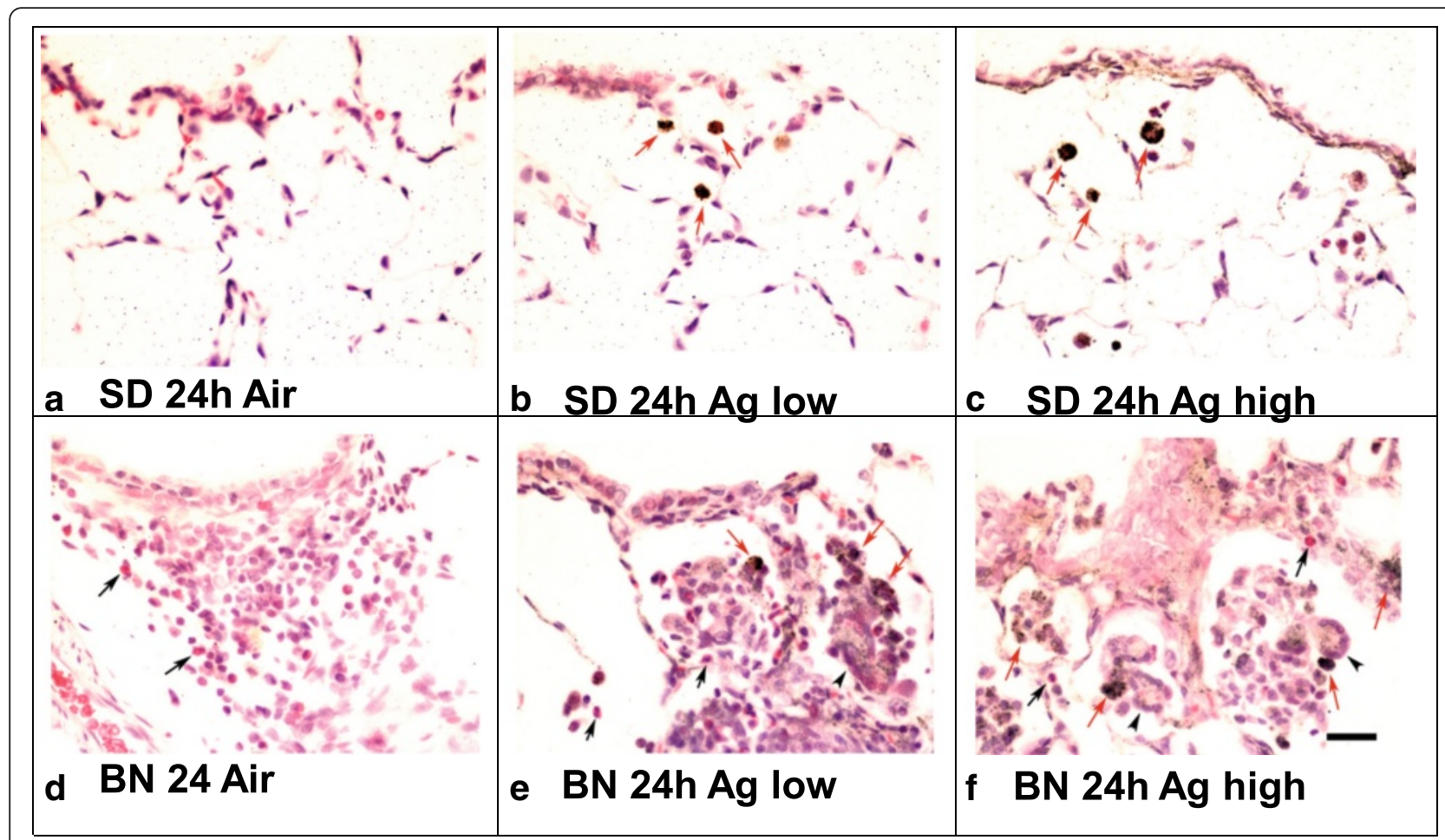

Fig. 3 Silver-enhancing and hematoxylin-eosin-stained Sprague-Dawley (SD) and Brown-Norway (BN) rat lung sections at $24 \mathrm{~h}$ post-treatment. Panels a \& d: SD and BN air control shows an absence of signal; silver-stained positive cells are seen as black or black brown positivity (red arrows). In Panel $\mathbf{b}$, SD at lung dose of $8 \mu \mathrm{g}$; in Panel $\mathbf{c}$, at lung dose of $28 \mu \mathrm{g}$ AgNPs and in Panel e, BN at lung dose $8 \mu \mathrm{g}$ and Panel $\mathbf{f}, 26 \mu \mathrm{g}$ AgNPs. Positive silver-stained cells are deposited in granuloma of BN lungs (arrow head pointing multi-nuclear giant cells). There are high levels of eosinophilic inflammation (black arrows) in BN lungs (internal scale bar $=20 \mu \mathrm{m}$ for all)

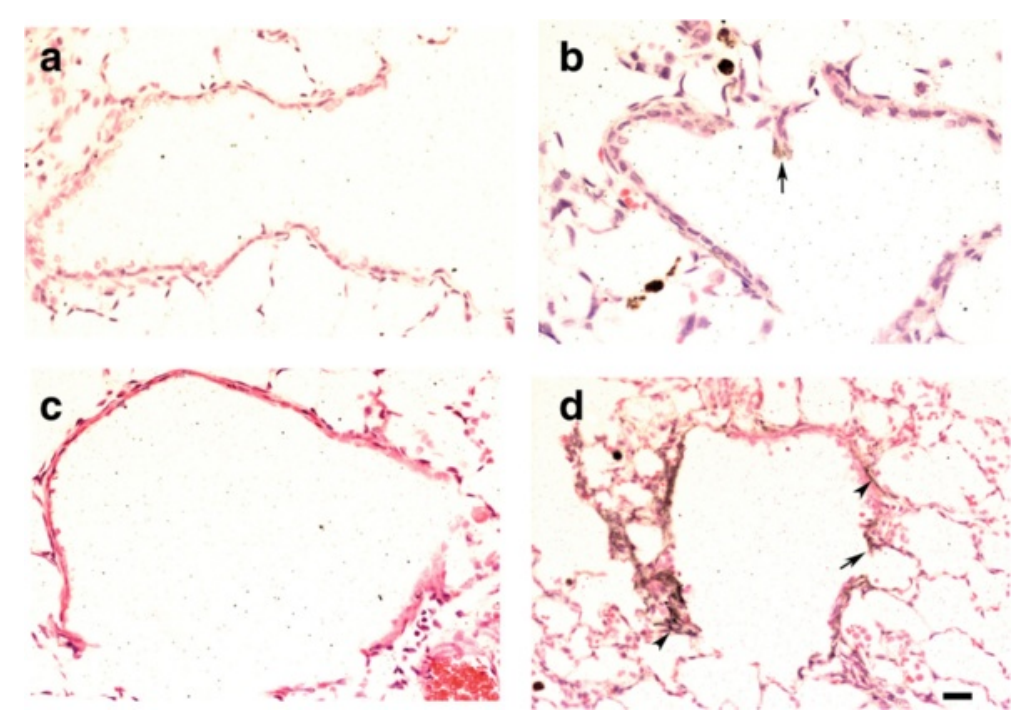

Fig. 4 Silver-enhancing and hematoxylin-eosin-stained terminal bronchioles of Sprague-Dawley rat lungs showing no signals in air control at $24 \mathrm{~h}$ and 7 days (Panels $\mathbf{a} \mathbf{\&} \mathbf{c}$ ). In Panel $\mathbf{b}$, a few black silver particles are deposited on the surface of epithelial cells (arrow) at $24 \mathrm{~h}$ after $28 \mathrm{\mu g}$ AgNPs inhalation. In Panel $\mathbf{d}$, more visible agglomerated black silver positivity were observed on the luminal surface and on surface epithelial cells (arrows) and subepithelial connective tissue (arrow heads) at 7 days post-8 $\mu \mathrm{g}$ AgNPs inhalation (internal scale bar $=20 \mu \mathrm{m}$ for all) 


\section{Sprague Dawley}

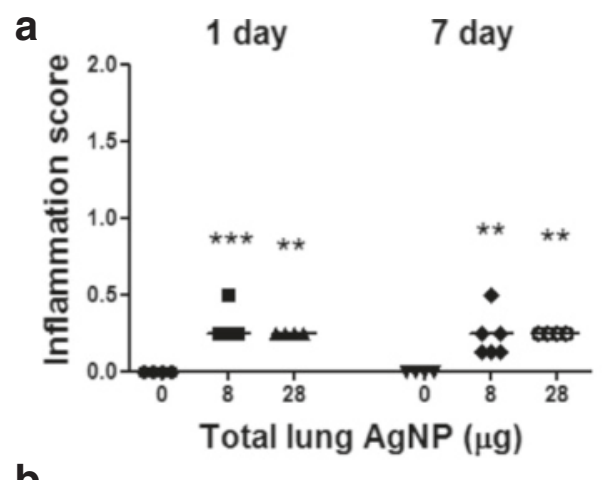

b

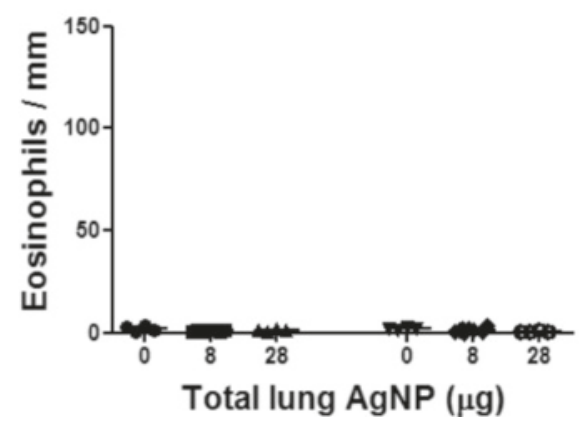

Brown Norway
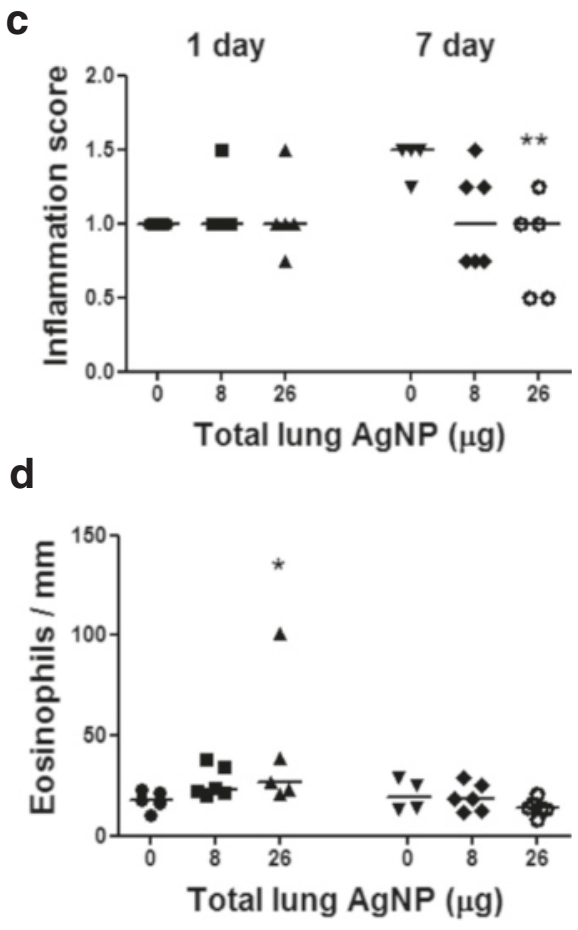

Fig. 5 Lung tissue inflammatory scores (Panels a $\boldsymbol{\&}$ b) and eosinophil counts per mm length of airway wall (Panels $\mathbf{c} \boldsymbol{\&} \mathbf{d}$ ) in Sprague Dawley and Brown Norway rats exposed to silver nanoparticles at 1 and 7 days post inhalation as a function of lung deposited doses of silver. Individual data-points shown for $8-12$ rats per group with horizontal bar showing mean. ${ }^{*} P<0.05$, ${ }^{* *} P<0.01,{ }^{* *} P<0.001$ versus the air only control (0) within each time-point

$B A L$ total protein, malonaldehyde (MDA), phospholipid and surfactant proteins

Total BAL protein increased in the SD rats at $28 \mu \mathrm{g}$ dose only $(P<0.001)$ at day 1 , and in the BN rats at both $8 \mu \mathrm{g}$ $(P<0.02)$ and $26 \mu \mathrm{g}(P<0.01)$. Total BAL protein levels returned to baseline levels by 7 daysay in both rat strains (Fig. 7 a \& e). In the SD rats, MDA increased at 1 day after inhalation of $8(P<0.03)$ and $28 \mu \mathrm{g}(P<0.01)$ of AgNP, with levels returning to baseline by day 7 . There was a similar trend in the $\mathrm{BN}$ rats but the increases were not significant (Fig. 7 b \& f).

In the SD rat, SP-D levels in whole BAL did not change at 1 day while at 7 days, there was a decrease after the high dose. In the BN rat, SP-D levels increased after the low dose but not after the high dose at 1 day (Fig. $7 \mathrm{~d} \& \mathrm{~h}$ ). There was no change in SP$\mathrm{D}$ at the $26 \mu \mathrm{g}$ dose at 7 days for the $\mathrm{BN}$ rats. Total phospholipid levels in the large aggregate fraction of BAL increased according to the dose of AgNPs exposed for both rat strains at day 1. By 7 day, phospholipid level remained elevated in the SD rat after the $26 \mu \mathrm{g}$ dose, while in the BN rat, levels had returned to baseline (Fig. 7 c \& g).

\section{BAL cytokines/chemokines}

Most of the changes in cytokine levels occurred at day 1 . In the SD rat, levels of IL-1 $\beta, \mathrm{KC}$, IL-17A, CCL2 (MCP1 ) and CCL3 (MIP-1 $\alpha$ ) increased at the $28 \mu \mathrm{g}$ dose, with increases also seen at $8 \mu \mathrm{g}$ for IL1 $\beta, \mathrm{KC}$ and CCL3 (Fig. 8). On the other hand, levels of IFN $\gamma$ fell in a dosedependent manner. CCL2 and CCL3 remained elevated at the high dose at day 7. In the $\mathrm{BN}$ rat, there were similar trends apart from an additional increase in IL-6 at day 1 at both 8 and $26 \mu \mathrm{g}$ doses. Levels of KC, CCL2 and CCL3 were generally higher in $\mathrm{BN}$ rat compared to SD rat. There were no changes in levels of IL-4, IL-13 and CCL-11 (eotaxin) (data not shown).

\section{Lung function}

There were no changes in large airway resistance (Rn), tissue damping $(\mathrm{G})$ or tissue elastance $(\mathrm{H})$ in the SD rats at either time-point compared with the air control at a physiological PEEP of $3 \mathrm{~cm} \mathrm{H}_{2} \mathrm{O}$, suggesting normal airway and parenchymal functioning of the SD lung (data not shown). In BN rats, at PEEP 3, Rn increased at both AgNP doses, although this was only statistically significant for the $8 \mu \mathrm{g}$ dose (Fig. 9 a). Increasing the PEEP 


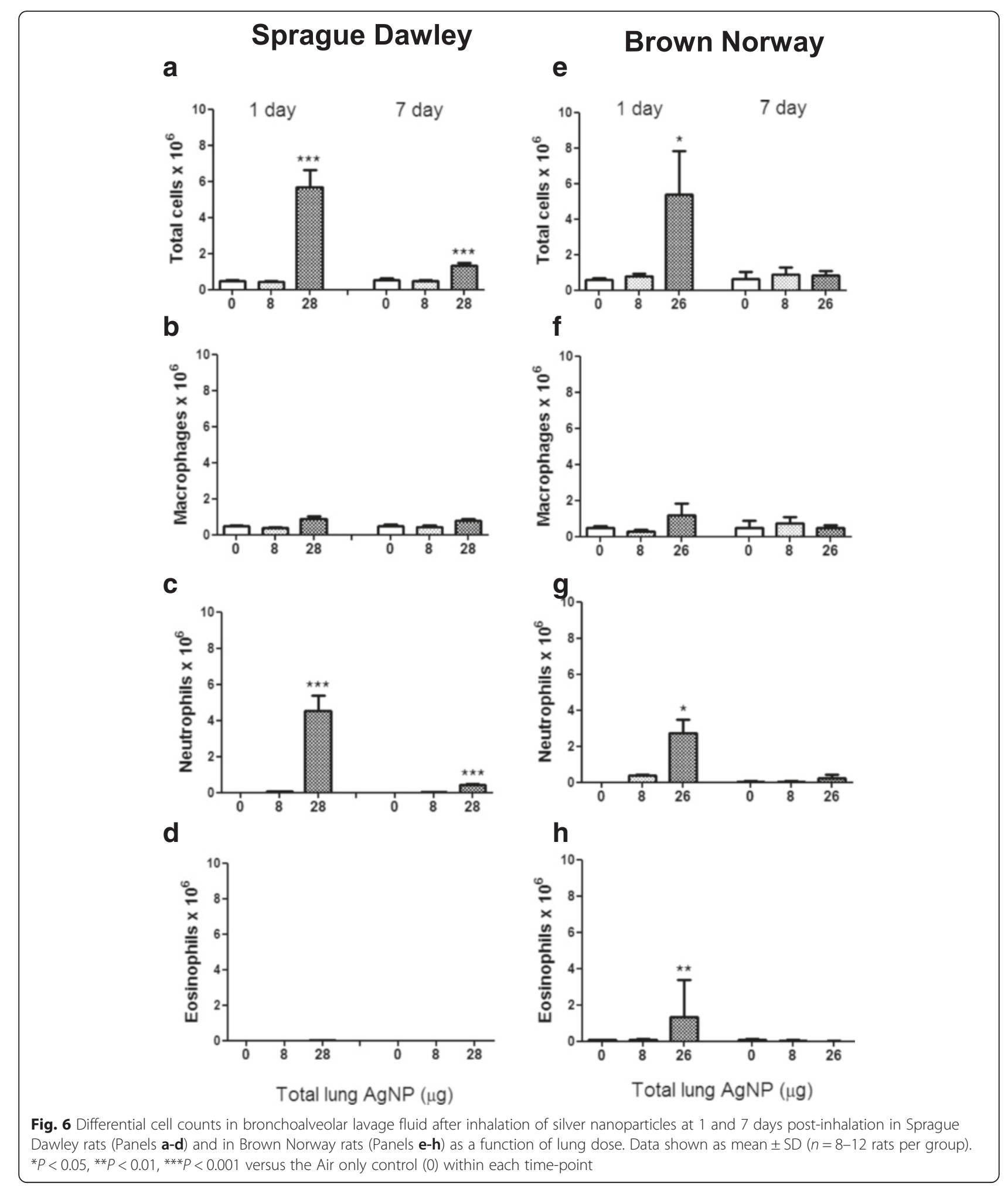

from 3 to 6 and $9 \mathrm{~cm} \mathrm{H}_{2} \mathrm{O}$ resolved the increase in $\mathrm{Rn}$ recorded at PEEP 3 (Fig. 9 b \& c). On the other hand, a small non-significant decrease in Rn at 7 days at PEEP 3 for the $8 \mu \mathrm{g}$ dose, was not resolved by PEEP suggesting some ongoing effects on lung function. There was also a significant increase in $\mathrm{H}$ for $\mathrm{BN}$ rats at PEEP 3 at the highest dose (Fig. $9 \mathrm{~d}$ ), suggesting effects on mechanical pulmonary function also originated in the parenchyma and that the $\mathrm{BN}$ rats had stiffer lungs. Again, increasing the PEEP from 3 to 6 and $9 \mathrm{~cm} \mathrm{H}_{2} \mathrm{O}$, resolved the 


\section{Sprague Dawley}

a

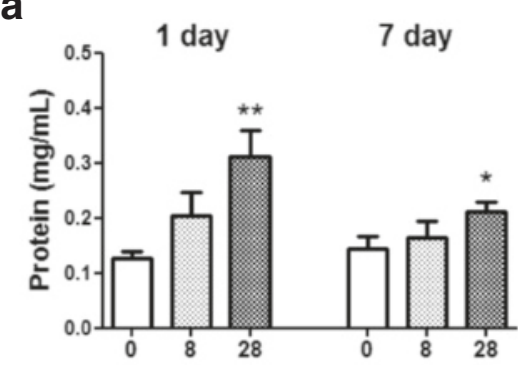

b

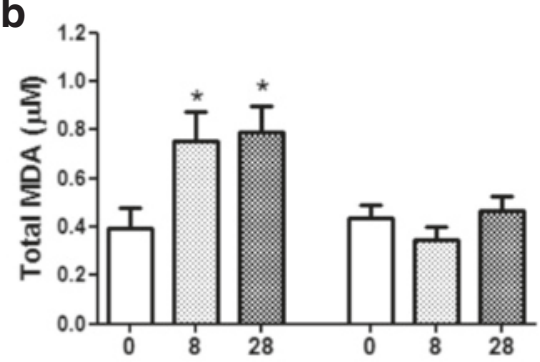

C

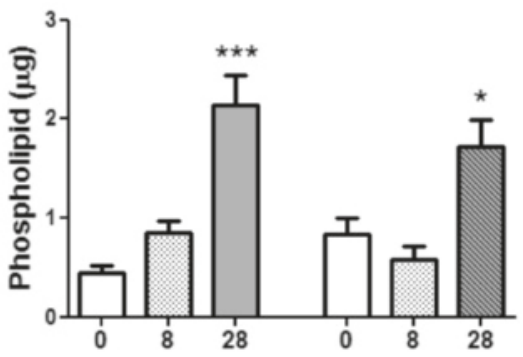

d

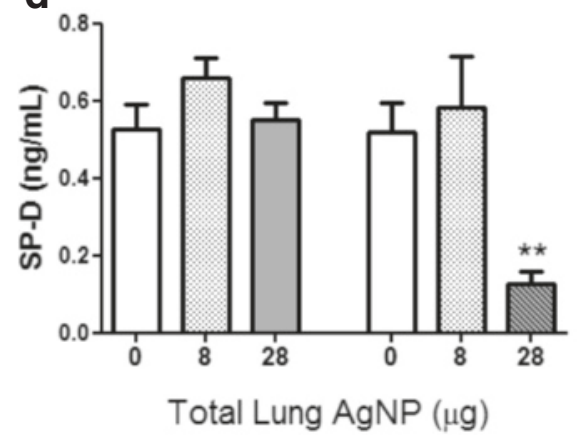

Brown Norway

e

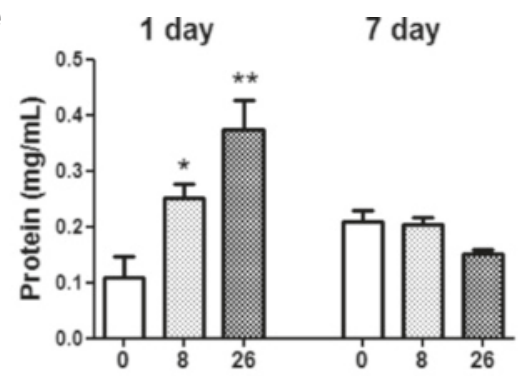

f

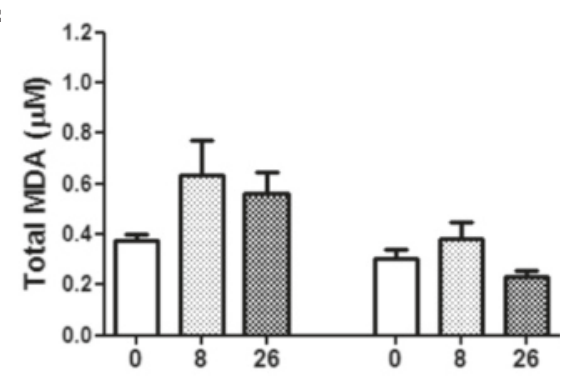

g

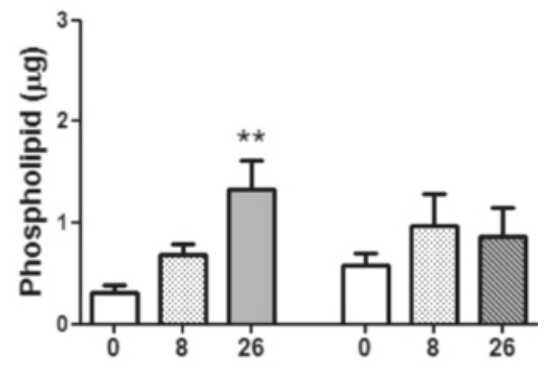

h

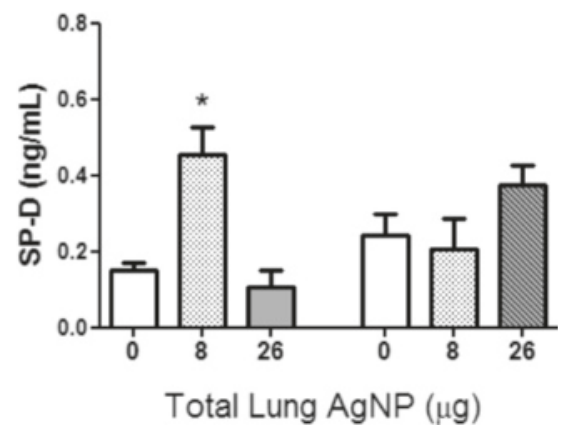

Fig. 7 Levels of total protein (Panels a \& e), malonaldehyde (MDA; Panels b \& $\mathbf{f}$ ) and surfactant protein D (SP-D; Panels $\mathbf{d}$ \& $\mathbf{h}$ ) in bronchoalveolar lavage fluid in Sprague Dawley and Brown Norway rats as a function of deposited lung dose of silver nanoparticles. Phospholipid levels (Panels c $\& \mathbf{g})$ were measured in the large aggregate fraction. Data shown as mean $\pm \mathrm{SD}$ ( $n=8-12$ rats per group). ${ }^{*} P<0.05,{ }^{* *} P<0.01,{ }^{* * *} P<0.001$ versus the Air only control (0) within each time-point

increases in $\mathrm{H}$, suggesting that this may be due to a recruitment phenomenon as before (Fig. 9 e \& f). Similar to the $\mathrm{SD}$ rats, there were no changes in $\mathrm{G}$ in the $\mathrm{BN}$ rats suggesting that no parenchymal distortion had occurred (data not shown).

\section{Discussion}

In this study, we report that inhalation of freshlygenerated silver nanoparticles of spherical shape of $15 \mathrm{~nm}$ diameter induced an acute pulmonary neutrophilic inflammation with the production of proinflammatory and 


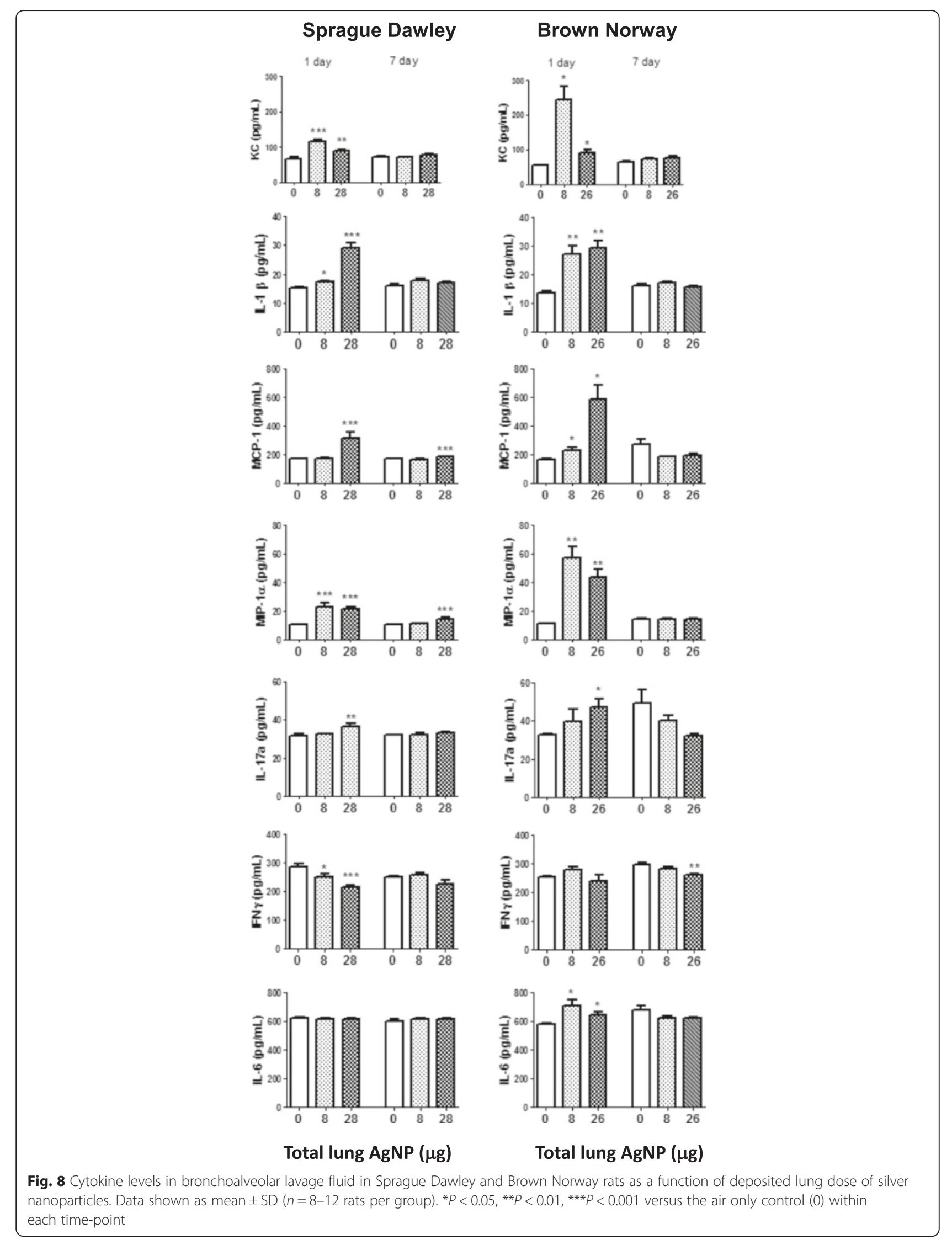




\section{Brow \\ Large Airway Resistance}

a

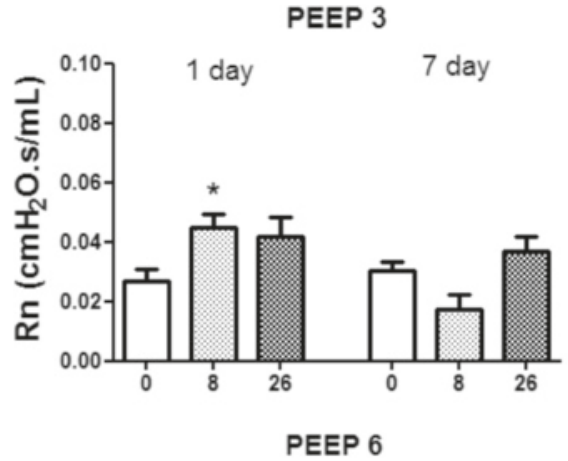

b

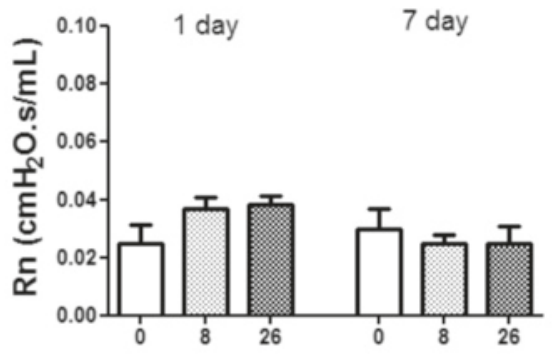

d

Tissue Elastance

PEEP 3
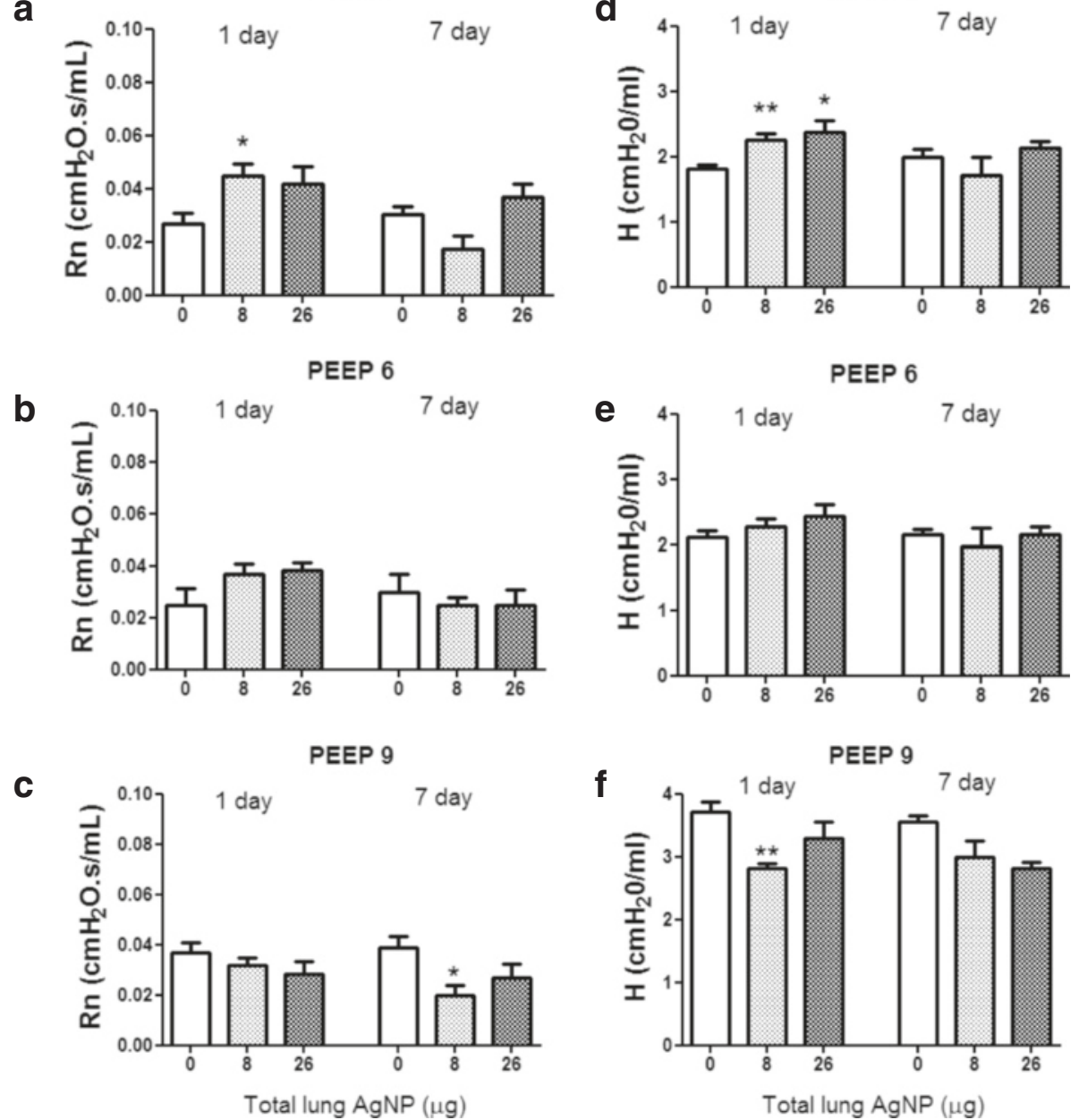

Fig. 9 Large airway resistance (Rn) (Panels a, b \& c) and tissue elastance (h) (Panels $\mathbf{d}$, e \& f) in Brown Norway rats exposed to silver nanoparticles at PEEP 3,6 and $9 \mathrm{~cm} \mathrm{H}_{2} \mathrm{O}$, at 1 and 7 days post inhalation as a function of lung deposited doses of silver. Data shown as mean \pm SD, $n=6$ rats per group. ${ }^{*} P<0.05$ and ${ }^{*} P<0.01$ versus the air only control (0) within each time-point

pro-neutrophilic cytokines in SD and $\mathrm{BN}$ rats. However, there were differences between the 2 strains in that the $\mathrm{BN}$ rat also showed an eosinophilic inflammation and also was the only strain to respond with a deterioration of lung function. In addition, our study further delineates the differential response of the lungs of these 2 rat strains to inhalation of silver nanospheres in relation to the clearance of silver from the lungs and the phospholipid and surfactant production.

\section{Silver tracing and clearance in the lungs}

The number of cells, particularly macrophages, containing silver increased with dose exposure in both strains, with the number of silver-positive cells in the $\mathrm{BN}$ rat 2 to 3-fold higher than in the SD rat at each time-point for the high dose. The uptake of nanoparticles into macrophages is likely to result in oxidative stress, the release of pro-inflammatorymediators and subsequent pulmonary inflammation $[15,29,30]$. Concomitantly, we found that the amount of silver in the lungs persisted to the seventh day, despite a small reduction by that time, but the levels found in the lungs of Brown-Norway rats were approximately $50 \%$ higher than in the lungs of Sprague-Dawley rats after the high dose exposure. The levels of silver measured in our Sprague-Dawley rats were higher than those previously reported in SpragueDawley or Fischer rats exposed to spark-generated uncoated silver nanoparticles of a similar size, partly due to the higher levels of exposure we delivered in our study $[2,6,7,31,32]$. The calculation of silver levels from the day 1 and day 7 measurements in the Sprague-Dawley rats indicate a clearance of $50 \%$, which is in a similar 
range to the clearance of $15 \mathrm{~nm}$ spark-produced AgNPs inhaled by Fischer rats at a lower concentration of $179 \mu \mathrm{g} / \mathrm{m}^{3}$ (compared to $\sim 700 \mu \mathrm{g} / \mathrm{m}^{3}$ for our study) for a similar exposure pattern (6 h/day for 4 days) of $62 \%$ between 1 and 7 days post exposure [6]. Clearance of such uncoated AgNPs have been reported to be much faster, for example in the study of Takenaka et al. [2], it was $62 \%$ one day after exposure, increasing to $96 \%$ on day 7 (clearance between 1 day and 7 days was $89 \%$ ) in Fischer rats. In a recent study of nebulised AgNPs of primary particle size $20 \mathrm{~nm}$ suspended in citrate buffer with a high mass concentration of $7.2 \mathrm{mg} / \mathrm{m}^{3}$ delivered to Sprague-Dawley rats for $6 \mathrm{~h}$, a clearance of $34 \%$ between day 1 and day 7 was reported [33]. The comparison between different studies is difficult because of differences in amount of exposure, dose of nanoparticles, method of generation of nanoparticle aerosols, particle size and even animal gender, but most of these studies would indicate that the silver persists for a period of at least 7 days after inhalation. In the study of Anderson et al. [33], one third of the initial silver inhaled persisted even at 56 days, and this was associated with a greater persistence of silver-positive macrophages at 21 and 56 days. In our study, the clearance between 1 day and 7 days for the Brown-Norway rat compared to the Sprague-Dawley rat was lower at $33 \%$, and was associated with a 2 to 3 -fold higher number of silver-containing lung macrophages compared to SD lungs. It is possible that the pre-inflamed lung of the Brown-Norway rat may retain more nanoparticles with a slower clearance rate leading to higher levels of silver found in the lungs when compared to the Sprague-Dawley rat.

\section{Phospholipid and surfactant levels and influence on lung function}

In accord with previous reports of the inhalation of nanoparticles of titanium oxide, silica or cadmium oxide or ultrafine diesel exhaust particles in rats or mice [34-37], we found that inhalation of AgNPs dose-dependently induced an increase in the levels of phospholipids and total protein in bronchoalveolar lavage fluid maximal at day 1 to a similar extent in both strains. Coating of the AgNPs with phospholipid may have important implications on pulmonary homeostasis by interfering with the biophysical surfactant function such as decreased adsorption of pulmonary surfactant at the air-liquid interface as has been observed for gold nanoparticles [23]. On the other hand, we found that the inhalation of AgNPs resulted in diametrically-different effects on the measured levels of SP-D in BAL fluid. While there was a decrease in SP-D levels in Sprague-Dawley rats at day 7 following the high dose exposure, there was an increase in SP-D levels in BAL from Brown-Norway rats at the low dose exposure at day 1 , with a non-significant increase at the high dose at day 7. Interestingly, the levels of SP-D at baseline in BAL fluid was nearly 3-fold higher in Sprague-Dawley rats compared to Brown-Norway rats. The reduction in SP-D in Brown-Norway rats may be due to increased SP-D turnover by alveolar macrophages, possibly as a result of binding to AgNPs [22]. The acute increase in SP-D levels in day 1 seen in Brown-Norway rat may represent an increased production from alveolar Type II cells. Increased amounts of SP-D may lead to increased aggregation of nanoparticles [21], hence targeting them towards macrophage and lung clearance [38]. In a recent study, we have also shown that incubating AgNPs with Curosurf ${ }^{R}$ reduced the amount of IL- 6 and IL- 8 release from human alveolar Type 1 cells exposed to these AgNPs [39].

Lung function changes only occurred in BrownNorway rats indicating a greater sensitivity of the airways and lungs to the effect of inhaled AgNPs, similar to the lung function responses observed with instillation of AgNPs [15]. Resolution of the increase in lung resistance recorded at low positive end-expiratory pressure (PEEP) by increasing PEEP suggests that this increase was a recruitment phenomenon which affected dynamic breathing that may be related to surfactant dysfunction rather than inherent forces in the lung which can occur following lung injury [40].

\section{Inhalation versus direct instillation}

The results of inhalation of AgNPs in the present study can be compared with our own work on the effect of direct instillation of these nanoparticles into the lungs [15]. In the previous study, we instilled AgNPs at $20 \mathrm{~nm}$ diameter capped with citrate or polyvinylpyrrolidone (PVP), the diameter nearest to the spark-generated particles at an intra-tracheal dose of $30 \mu \mathrm{g}$ in both strains. Indeed, the pattern of responses in these 2 strains in terms of the inflammatory response and of lung function changes were similar for both strains, albeit a lesser response by the inhaled route when a maximal dose of 26-28 $\mu \mathrm{g}$ was deposited in the lungs. The highest inhaled dose used at which we saw an effect was acquired over a period of $12 \mathrm{~h}$ of inhalation, while for the instillation, a larger bolus dose was administered over seconds. Thus, with the instilled dose of both citrate and pvpcapped $20 \mathrm{~nm}$ silver nanoparticles, we saw a neutrophilic response at day 1 in both strains but only eosinophilic response significant at day 7 in Sprague-Dawley rats. Similarly, there was an increase in protein concentration and levels of MDA in bronchoalveolar lavage fluid, with increased levels of $\mathrm{KC}$ at day 1 in both strains. Changes in lung function were only seen in Brown-Norway rats at day 1 also, but not in Sprague-Dawley rats, changes that were similar as those observed in the current study. The inflammatory data we have observed are simialr to those reported from a study of Silva et al. [41] who 
reported that instillation of AgNPs into the lungs of rats induced an inflammatory response at day 7 with resolution by day 21 , while at day 56 , there was no inflammatory response and no evidence of airway wall remodelling. By contrast, Song et al. [10] reported that in SpragueDawley rats exposed to spark-generated AgNP aerosol, there was persistence of mild inflammation observed at 12 weeks. Longer term exposure studies are needed.

\section{Conclusions}

The pre-existing inflammatory state of the BrownNorway rat is likely to underlie the increased amount of silver retained in the lungs with a reduced clearance rate that may underlie the increased inflammatory response, induction of SP-D and phospholipid and airway and parenchymal dysfunction observed in this rat strain but not in Sprague-Dawley rats. Our findings would indicate that inhalation of AgNPs in people with pre-existing inflammation in the lungs such as asthma patients or those with chronic obstructive pulmonary disease would lead to a greater degree of inflammation with heightened consequences on lung function.

\section{Acknowledgements}

This research was funded by grants from US National Institute for Environmental Health Sciences grant number U19ES019536 (http:// www.niehs.nih.gov/research/supported/index.cfm), and from the UK National Environmental Research Council grant NE/H012893 (http://www.nerc.ac.uk/ research/). AEP was funded by a European Research Council starting grant No 257182.

\section{Authors' contribution}

KFC: Involvement in conception, design and major part of the writing of the manuscript; JS, BA, FH \& CG carried out the in-vivo exposure studies; JW, AH \& RS setting-up the spark generation of nanoparticles and analysis of particles; CG, NGM, BL \& RS measurement of silver in lungs by ICPMS; RD, JZ \& JS the histological preparation and measurements; JG \& JZ the measurement of malonylaldehyde; JS \& FH lung function measurements, counting of inflammatory cells and cytokine assays; and AP, TDT, AG, RS \& KFC supervised various aspects of measurements. All authors critically read and approved the final manuscript.

\section{Competing interests}

The authors declare that they have no competing interests.

\begin{abstract}
Author details
${ }^{1}$ Airways Disease, National Heart \& Lung Institute, Imperial College London, Dovehouse St, LondonSW3 6LYUK. ${ }^{2}$ Nanoparticle Inhalation Research Group, Public Health England, Oxfordshire, UK. 'Department of Material Science, Chemistry and the London Centre for Nanotechnology, Imperial College, LondonSW3UK. ${ }^{4}$ Department of Clinical Biochemistry, Imperial College Healthcare NHS Trust, Charing Cross Hospital, LondonW6 8RFUK. ${ }^{5}$ Nicholas School of Environment \& Duke Global Health Institute, Duke University, Durham, USA. ${ }^{6}$ Department of Pharmacology and Toxicology, Rutgers University, Piscataway, NJ, USA
\end{abstract}

Received: 30 March 2016 Accepted: 14 July 2016 Published online: 19 July 2016

\section{References}

1. Quadros ME, Marr LC. Silver nanoparticles and total aerosols emitted by nanotechnology-related consumer spray products. Environ Sci Technol. 2011:45:10713-9.
2. Takenaka S, Karg E, Roth C, Schulz H, Ziesenis A, Heinzmann U, Schramel P, Heyder J. Pulmonary and systemic distribution of inhaled ultrafine silver particles in rats. EnvironHealth Perspect. 2001;109 Suppl 4:547-51.

3. Hyun JS, Lee BS, Ryu HY, Sung JH, Chung KH, Yu IJ. Effects of repeated silver nanoparticles exposure on the histological structure and mucins of nasal respiratory mucosa in rats. Toxicol Lett. 2008;182:24-8.

4. Anderson DS, Silva RM, Lee D, Edwards PC, Sharmah A, Guo T, Pinkerton KE, Van Winkle LS. Persistence of silver nanoparticles in the rat lung: Influence of dose, size, and chemical composition. Nanotoxicology. 2014;9:1-12

5. Braakhuis HM, Cassee FR, Fokkens PH, de la Fonteyne LJ, Oomen AG, Krystek $\mathrm{P}$, de Jong $\mathrm{WH}$, van Loveren $\mathrm{H}$, Park MV. Identification of the appropriate dose metric for pulmonary inflammation of silver nanoparticles in an inhalation toxicity study. Nanotoxicology. 2015;10:1-11.

6. Braakhuis HM, Gosens I, Krystek P, Boere JA, Cassee FR, Fokkens PH, Post JA, van Loveren H, Park MV. Particle size dependent deposition and pulmonary inflammation after short-term inhalation of silver nanoparticles. Part Fibre Toxicol. 2014;11:49.

7. Ji JH, Jung JH, Kim SS, Yoon JU, Park JD, Choi BS, Chung YH, Kwon IH, Jeong J, Han BS, et al. Twenty-eight-day inhalation toxicity study of silver nanoparticles in Sprague-Dawley rats. Inhal Toxicol. 2007;19:857-71.

8. Sung JH, Ji JH, Yoon JU, Kim DS, Song MY, Jeong J, Han BS, Han JH, Chung YH, Kim J, et al. Lung function changes in Sprague-Dawley rats after prolonged inhalation exposure to silver nanoparticles. Inhal Toxicol. 2008;20:567-74.

9. Kim JS, Sung JH, Ji JH, Song KS, Lee JH, Kang CS, Yu IJ. In vivo genotoxicity of silver nanoparticles after 90-day silver nanoparticle inhalation exposure. Saf Health Work. 2011;2:34-8.

10. Song KS, Sung JH, Ji JH, Lee JH, Lee JS, Ryu HR, Lee JK, Chung YH, Park HM, Shin BS, et al. Recovery from silver-nanoparticle-exposure-induced lung inflammation and lung function changes in Sprague Dawley rats. Nanotoxicology. 2013;7:169-80.

11. Sung JH, Ji JH, Song KS, Lee JH, Choi KH, Lee SH, Yu IJ. Acute inhalation toxicity of silver nanoparticles. Toxicol Ind Health. 2011;27:149-54.

12. Stebounova LV, Adamcakova-Dodd A, Kim JS, Park H, O'Shaughnessy PT, Grassian $\mathrm{VH}$, Thorne PS. Nanosilver induces minimal lung toxicity or inflammation in a subacute murine inhalation model. Part Fibre Toxicol. 2011;8:5.

13. Roberts JR, McKinney W, Kan H, Krajnak K, Frazer DG, Thomas TA, Waugh S, Kenyon A, MacCuspie Rl, Hackley VA, Castranova V. Pulmonary and cardiovascular responses of rats to inhalation of silver nanoparticles. J Toxicol Environ Health A. 2013;76:651-68.

14. Haberl N, Hirn S, Wenk A, Diendorf J, Epple M, Johnston BD, Krombach F, Kreyling WG, Schleh C. Cytotoxic and proinflammatory effects of PVP-coated silver nanoparticles after intratracheal instillation in rats. Beilstein J Nanotechnol. 2013;4:933-40

15. Seiffert J, Hussain F, Wiegman C, Li F, Bey L, Baker W, Porter A, Ryan MP, Chang Y, Gow A, et al. Pulmonary toxicity of instilled silver nanoparticles: influence of size, coating and rat strain. PLoS One. 2015;10:e0119726.

16. Wang X, Ji Z, Chang CH, Zhang H, Wang M, Liao YP, Lin S, Meng H, Li R, Sun $B$, et al. Use of coated silver nanoparticles to understand the relationship of particle dissolution and bioavailability to cell and lung toxicological potential. Small. 2014;10:385-98.

17. Elwood W, Lotvall JO, Barnes PJ, Chung KF. Characterisation of allergeninduced inflammation and bronchial hyperresponsiveness in sensitised Brown-Norway rats. J Allergy Clin Immunol. 1991;88:951-60.

18. Waserman S, Olivenstein R, Renzi P, Xu LJ, Martin JG. The relationship between late asthmatic responses and antigen-specific immunoglobulin. J Allergy Clin Immunol. 1992;90:661-9.

19. Careau E, Sirois J, Bissonnette EY. Characterization of lung hyperresponsiveness, inflammation, and alveolar macrophage mediator production in allergy resistant and susceptible rats. AmJRespir Cell MolBiol. 2002;26:579-86

20. Noritake S, Ogawa K, Suzuki G, Ozawa K, Ikeda T. Pulmonary inflammation in brown Norway rats: possible association of environmental particles in the animal room environment. Exp Anim. 2007;56:319-27.

21. Kendall M, Ding P, Mackay RM, Deb R, McKenzie Z, Kendall K, Madsen J, Clark H. Surfactant protein D (SP-D) alters cellular uptake of particles and nanoparticles. Nanotoxicology. 2013;7:963-73.

22. Ruge CA, Schaefer UF, Herrmann J, Kirch J, Canadas O, Echaide M, Perez-Gil J, Casals C, Muller R, Lehr CM. The interplay of lung surfactant proteins and lipids assimilates the macrophage clearance of nanoparticles. PLoS One. 2012;7:e40775.

23. Theodorou IG, Ryan MP, Tetley TD, Porter AE. Inhalation of silver nanomaterials-seeing the risks. Int J Mol Sci. 2014;15:23936-74. 
24. Buckley AHA, Warren J, Guo C, Smith R. Size dependent deposition of inhaled nanoparticles in the rat respiratory tract using a new nose-only exposure system. Aerosol Sci \& Technol. 2016;50:1-10.

25. Anjilvel S, Asgharian B. A multiple-path model of particle deposition in the rat lung. Fundam Appl Toxicol. 1995;28:41-50.

26. Hantos Z, Adamicza A, Govaerts E, Daroczy B. Mechanical impedances of lungs and chest wall in the cat. J Appl Physiol (1985). 1992;73:427-33.

27. Veldhuizen RA, Inchley K, Hearn SA, Lewis JF, Possmayer F. Degradation of surfactant-associated protein B (SP-B) during in vitro conversion of large to small surfactant aggregates. Biochem J. 1993;295(Pt 1):141-7.

28. Bartlett D, Glaser M, Welti R. Membrane penetration depth and lipid phase preference of acyl-labeled dansyl phosphatidylcholines in phosphatidylcholine vesicles. Biochim Biophys Acta. 1997;1328:48-54.

29. Mukherjee D, Royce SG, Sarkar S, Thorley A, Schwander S, Ryan MP, Porter $A E$, Chung KF, Tetley TD, Zhang J, Georgopoulos PG. Modeling in vitro cellular responses to silver nanoparticles. J Toxicol. 2014;2014:852890.

30. Sarkar S, Leo BF, Carranza C, Chen S, Rivas-Santiago C, Porter AE, Ryan MP, Gow A, Chung KF, Tetley TD, et al. Modulation of human macrophage responses to mycobacterium tuberculosis by silver nanoparticles of different size and surface modification. PLoS One. 2015;10:e0143077.

31. Sung JH, Ji JH, Park JD, Yoon JU, Kim DS, Jeon KS, Song MY, Jeong J, Han BS, Han JH, et al. Subchronic inhalation toxicity of silver nanoparticles. Toxicol Sci. 2009;108:452-61.

32. Kwon JT, Minai-Tehrani A, Hwang SK, Kim JE, Shin JY, Yu KN, Chang SH, Kim DS, Kwon YT, Choi IJ, et al. Acute pulmonary toxicity and body distribution of inhaled metallic silver nanoparticles. Toxicol Res. 2012;28:25-31.

33. Anderson DS, Patchin ES, Silva RM, Uyeminami DL, Sharmah A, Guo T, Das GK, Brown JM, Shannahan J, Gordon T, et al. Influence of particle size on persistence and clearance of aerosolized silver nanoparticles in the rat lung. Toxicol Sci. 2015;144:366-81.

34. Rehn B, Seiler F, Rehn S, Bruch J, Maier M. Investigations on the inflammatory and genotoxic lung effects of two types of titanium dioxide: untreated and surface treated. Toxicol Appl Pharmacol. 2003;189:84-95.

35. Kawada H, Horiuchi T, Shannon JM, Kuroki Y, Voelker DR, Mason RJ. Alveolar type II cells, surfactant protein A (SP-A), and the phospholipid components of surfactant in acute silicosis in the rat. Am Rev Respir Dis. 1989;140:460-70.

36. Alessandrini F, Ziesenis A, Takenaka S, Karg E, Heyder J, Ring J, Behrendt H. Effects of inhaled $\mathrm{CdO}$ particles on the sphingolipid synthesis of rat lungs. Inhal Toxicol. 2003;15:343-56.

37. Eskelson CD, Chvapil M, Strom KA, Vostal JJ. Pulmonary phospholipidosis in rats respiring air containing diesel particulates. Environ Res. 1987:44:260-71.

38. Vuk-Pavlovic Z, Standing JE, Crouch EC, Limper AH. Carbohydrate recognition domain of surfactant protein D mediates interactions with Pneumocystis carinii glycoprotein A. Am J Respir Cell Mol Biol. 2001;24:475-84.

39. Sweeney S, Leo BF, Chen S, Abraham-Thomas N, Thorley AJ, Gow A, Schwander S, Zhang JJ, Shaffer MS, Chung KF, et al. Pulmonary surfactant mitigates silver nanoparticle toxicity in human alveolar type-l-like epithelial cells. Colloids Surf B: Biointerfaces. 2016;145:167-75.

40. Massa CB, Scott P, Abramova E, Gardner C, Laskin DL, Gow AJ. Acute chlorine gas exposure produces transient inflammation and a progressive alteration in surfactant composition with accompanying mechanical dysfunction. Toxicol Appl Pharmacol. 2014;278:53-64.

41. Silva RM, Anderson DS, Peake J, Edwards PC, Patchin ES, Guo T, Gordon T, Chen LC, Sun X, Van Winkle LS, Pinkerton KE. Aerosolized silver nanoparticles in the rat lung and pulmonary responses over time. Toxicol Pathol. 2016:44:673.

\section{Submit your next manuscript to BioMed Central and we will help you at every step:}

- We accept pre-submission inquiries

- Our selector tool helps you to find the most relevant journal

- We provide round the clock customer support

- Convenient online submission

- Thorough peer review

- Inclusion in PubMed and all major indexing services

- Maximum visibility for your research

Submit your manuscript at www.biomedcentral.com/submit
Biomed Central 